\title{
Enhanced hydrological cycle increases ocean heat uptake and moderates
} \section{transient climate change}

Maofeng Liu ${ }^{*}$, Gabriel Vecchi ${ }^{2,3}$, Brian Soden ${ }^{1}$, Wenchang Yang ${ }^{2}$, Bosong Zhang ${ }^{1}$ ${ }^{3}$ Princeton Environmental Institute, Princeton University, Princeton, NJ

$7 \quad$ *Corresponding Author: Maofeng Liu (mx11744@miami.rsmas.edu; maofengliu2012@gmail.com) 
8 Abstract

9 The large-scale moistening of the atmosphere in response to increasing greenhouse gases amplifies

10 the existing patterns of precipitation minus evaporation (P-E) which, in turn, amplifies the spatial

11 contrast in sea surface salinity (SSS). Through a series of $\mathrm{CO}_{2}$ doubling experiments, we

12 demonstrate that surface salinification driven by the amplified dry conditions $(\mathrm{P}-\mathrm{E}<0)$, primarily

13 in the subtropical ocean, accelerates ocean heat uptake. The salinification also drives the

14 sequestration of upper-level heat into the deeper ocean, reducing the thermal stratification and

15 increasing the heat uptake through a positive feedback. The change in Atlantic Meridional

16 Overturning Circulation due to salinification plays a secondary role in heat uptake. Consistent

17 with the heat uptake changes, the transient climate response would increase by approximately $0.4 \mathrm{~K}$

18 without this process. Observed multi-decadal changes in subsurface temperature and salinity

19 resembles those simulated, indicating that anthropogenically-forced changes in salinity are likely

20 enhancing the ocean heat uptake. 


\section{Main}

The increased concentration of atmospheric greenhouse gases has reduced the longwave

23 cooling of the Earth's climate system to space, resulting in planetary warming, which works to

24 eventually bring the climate towards a new - warmer - equilibrium ${ }^{1}$. It has been estimated that

25 over $90 \%$ of the top-of-atmosphere energy imbalance is captured by the ocean as increased ocean

26 heat content $(\mathrm{OHC})^{2,3}$. The resulting upper ocean warming can enhance the thermal stratification

27 of the ocean ${ }^{4}$, and thus act to dampen mode water formation ${ }^{5}$. A recent study ${ }^{2}$ summarizing

28 observation-based $\mathrm{OHC}$ estimates $^{6-11}$ and climate model simulations from the Coupled Model

29 Intercomparison Project Phase 5 (CMIP5) ${ }^{12-15}$ claims a stronger rate of ocean warming over the

30 period of 2005-2017 $\left(0.54-0.64 \mathrm{~W} \mathrm{~m}^{-2}\right)$ relative to the period of 1971-2010 $\left(0.36-0.39 \mathrm{~W} \mathrm{~m}^{-2}\right)$.

31 Furthermore, in both observationally constrained $\mathrm{OHC}$ data ${ }^{16}$ and climate model simulations ${ }^{17}$, a

32 substantial portion of increased $\mathrm{OHC}$ is found in tropics and subtropics (i.e., equatorward of $40^{\circ}$

33 latitude). This creates a conundrum: given the stably stratified low-latitude ocean, how does the

34 warming water get subducted to produce subtropical ocean heat uptake in spite of further

35 stabilization from upper ocean warming ${ }^{4,18}$ ?

36 We propose that the amplification of the spatial pattern of sea surface salinity (SSS) ${ }^{19-23}$

37 resulting from the enhancement of global hydrological cycle ${ }^{24}$ provides an important supporting

38 mechanism for the rate of ocean heat uptake. A robust consequence of anthropogenic warming is

39 the increase of atmospheric moisture content controlled by the Clausius-Clapeyron (CC) relation,

40 leading to the strengthening of the water cycle expressed as the amplification of the existing

41 patterns of surface freshwater fluxes [precipitation minus evaporation $(\mathrm{P}-\mathrm{E})]^{24}$. The enhancement

42 of $\mathrm{P}-\mathrm{E}$ amplifies the mean state, that is, "dry gets drier and wet gets wetter" 24 . Since SSS in part

43 reflects large-scale patterns of $\mathrm{P}-\mathrm{E}$, the enhancement of the global hydrological cycle acts to 
44 amplify patterns of SSS: "fresh gets fresher and salty gets saltier"19,20,25,26. Analyses of long-term

45 observations of SSS have revealed that the spatial changes of SSS largely resemble the 46 climatological SSS distribution ${ }^{19}$. We hypothesize that salinification of the subtropical surface

47 ocean provides an important buoyancy sink that helps compensate the stabilizing impact of upper

48 ocean warming and enhance low-latitude heat uptake, and thus the enhancement of the

49 hydrological cycle moderates the transient climate change.

In this study, we quantify the impact of the sea surface salinification on ocean heat uptake

51 and transient climate warming using a global coupled ocean-atmosphere climate model [the

52 Forecast-oriented Low Ocean Resolution version of the Coupled Model version 2.5 (FLOR)]

53 developed at the Geophysical Fluid Dynamics Laboratory ${ }^{17,27}$. We conduct a suite of transient $\mathrm{CO}_{2}$

54 doubling experiments in which the atmospheric $\mathrm{CO}_{2}$ concentration is increased by $1 \%$ per year

55 until doubling. The experiments include a baseline run using the standard configuration of FLOR

56 (labelled as STD) and a perturbation run using a modified FLOR in which the SSS is nudged to

57 the seasonally-varying control climatology from the STD run on global scales (labelled as fixed-

58 SSS-GL see Methods for details). Differences in $\mathrm{CO}_{2}$ response between these two configurations

59 highlight the influences of SSS changes on transient climate warming.

60 Compared to the STD version, the fixed-SSS-GL version shows a greater increase of global

61 mean surface temperature with a larger transient climate response (TCR) by $0.4 \mathrm{~K}$, highlighting

62 the role of $\mathrm{CO}_{2}$-induced SSS changes in reducing the rate of surface warming in response to $\mathrm{CO}_{2}$

63 doubling (Fig. 1). The mean difference $(0.002 \mathrm{~K})$ in annual global mean surface temperature

64 between the 100-year STD and fixed-SSS-GL control runs is three orders of magnitude smaller

65 than the difference in TCR, suggesting the relatively small climatological effect of fixing SSS on 
66 unforced simulations of surface temperature (See Supplementary Text 1 and Supplementary Fig.

671 for details).

68

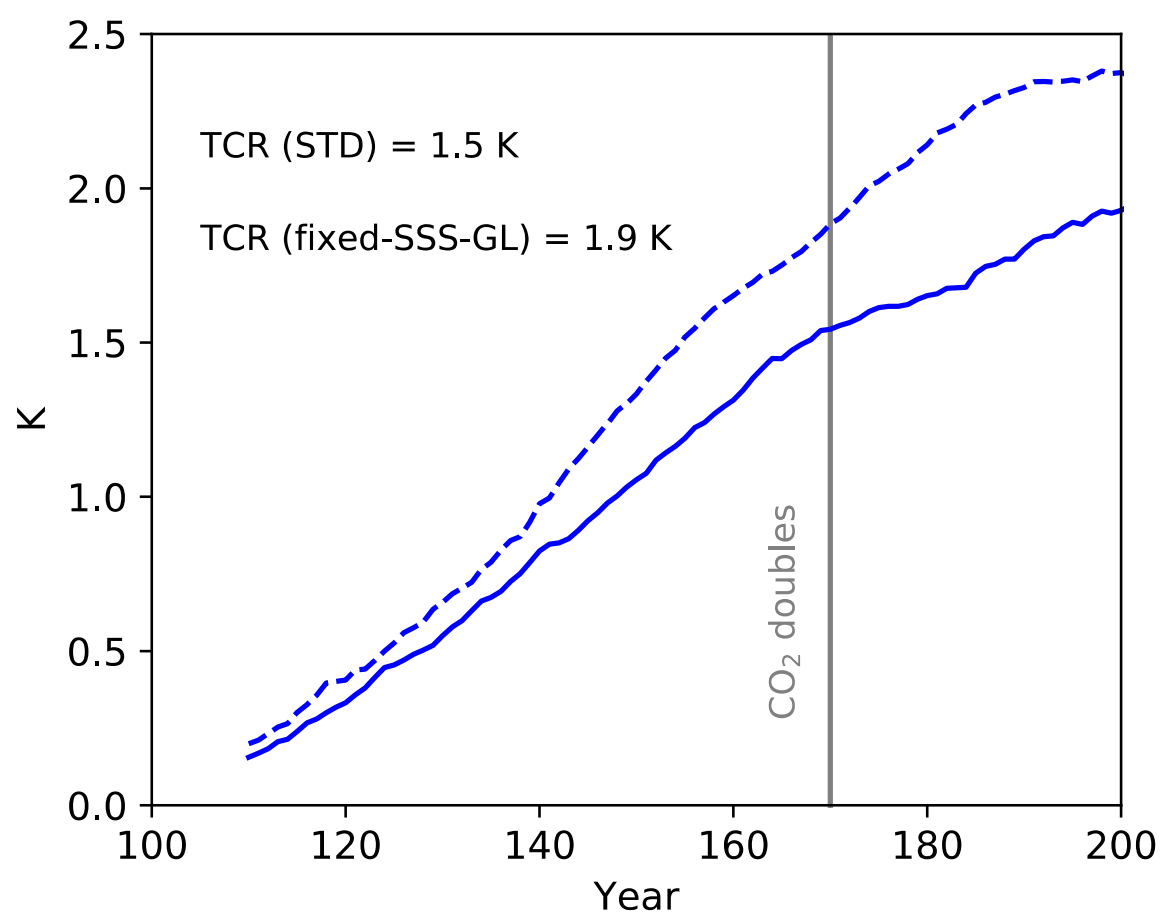

69

70 Fig. 1. Response of surface temperature to transient $\mathrm{CO}_{2}$ forcing. Time series of global mean

71 surface temperature changes $\left({ }^{\circ} \mathrm{C}\right)$ in response to a $1 \%$ annual increase in $\mathrm{CO}_{2}$ concentration for the

72 STD (solid line) and fixed-SSS-GL (dashed line) version. Data are plotted as 20-year running

73 mean.

74 

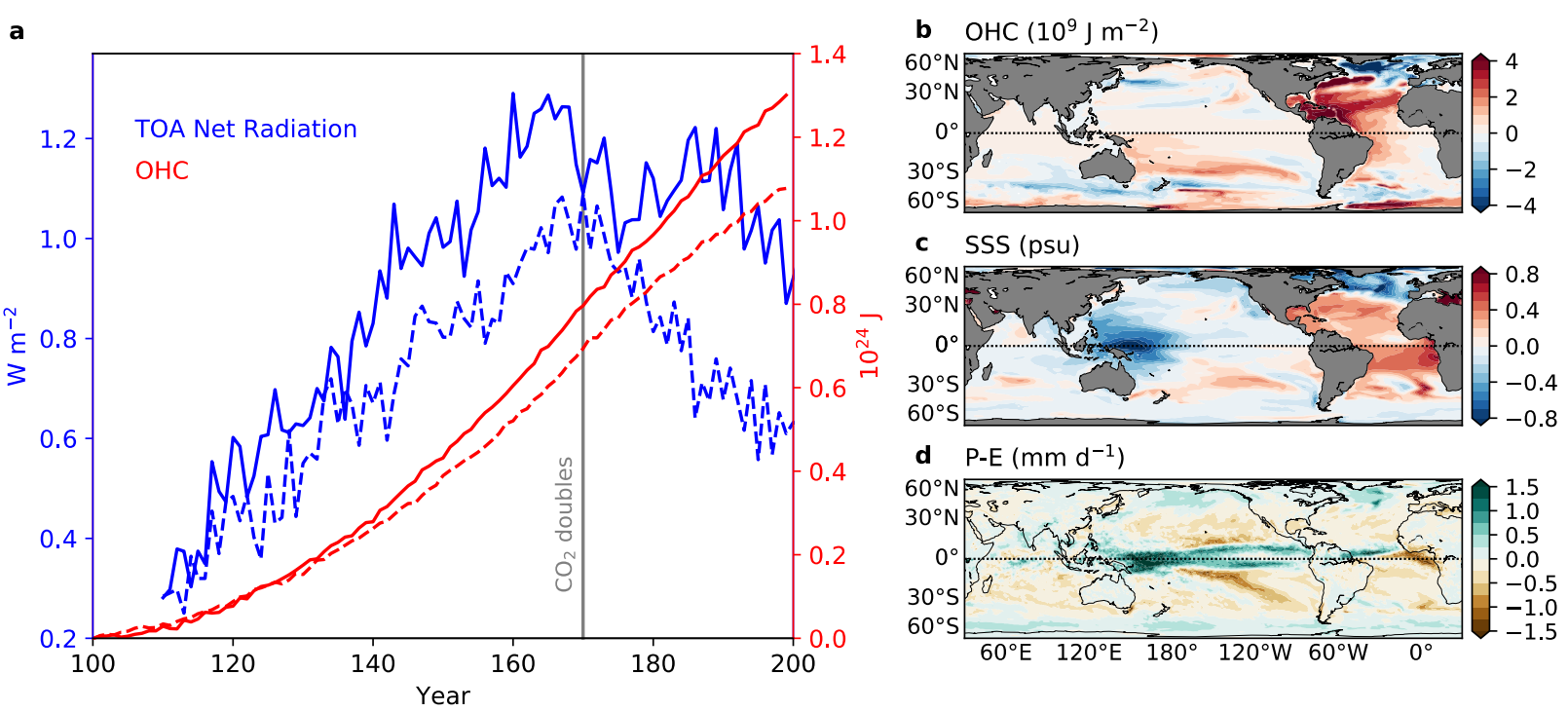

Fig. 2. Impact of fixed SSS on the response of $\mathrm{OHC}$ and TOA net radiation to $\mathrm{CO}_{2}$ forcing.

a, Annual series of changes in TOA net radiation $\left(\mathrm{W} \mathrm{m}^{-2}\right.$; blue $)$ and $\mathrm{OHC}\left(10^{24} \mathrm{~J}\right.$; red $)$ in response to a $1 \%$ annual increase in $\mathrm{CO}_{2}$ for the STD (solid line) and fixed-SSS-GL (dashed line) version. The grey line indicates year 170 when the $\mathrm{CO}_{2}$ doubles. The TOA net radiation is plotted as 10 -

80 year running mean. $\mathbf{b}$, Difference in the response of $\mathrm{OHC}\left(10^{9} \mathrm{~J} \mathrm{~m}^{-2}\right)$ to $\mathrm{CO}_{2}$ doubling between the

81 STD and fixed-SSS-GL version. The response is computed using years 161-180 from the $\mathrm{CO}_{2}$ run

82 while years 101-200 from the control run. c, The same as $\mathbf{b}$, but for difference in the response of 83 sea surface salinity (SSS; psu). d, The response of $\mathrm{P}-\mathrm{E}\left(\mathrm{mm} \mathrm{d}^{-1}\right)$ pattern to $\mathrm{CO} 2$ doubling for the 84 STD version.

The greater surface warming in the fixed-SSS-GL experiment relative to the STD run,

87 given the similar climate feedback parameter (-1.6 and $-1.5 \mathrm{~W} \mathrm{~m}^{-2} \mathrm{~K}^{-1}$ for the STD and fixed-SSS-

88 GL version, respectively; see Methods, Supplementary Text 2 and Supplementary Fig. 2 for 89 details), should result in a larger radiative response of the climate system. Based on the top-of90 atmosphere (TOA) energy balance $[\mathrm{R}(\mathrm{t})=\mathrm{Q}(\mathrm{t})+\lambda \Delta \mathrm{T}(\mathrm{t})$ where $\mathrm{R}$ is the net radiation at the TOA, 
$91 \mathrm{Q}$ is the radiative forcing, $\lambda$ is the climate feedback parameter, $\Delta \mathrm{T}$ is the surface warming and $\mathrm{t}$ is

92 time], a lower radiative imbalance at the TOA occurs when SSS is fixed given the same $\mathrm{CO}_{2-}$

93 induced radiative forcing (Fig. 2a). This indicates the fixed-SSS-GL version has a much lower

94 ocean heat uptake efficiency ${ }^{28,29}$, defined as the ratio of net radiation at the TOA to the global

95 surface temperature increase. Consistently, the fixed-SSS-GL experiment shows a smaller increase

96 of OHC in comparison with the STD experiment (Fig. 2a). Similar to global mean surface

97 temperature, there is a relatively small effect of fixing SSS on control simulations of net radiation

98 at the TOA and OHC (see Supplementary Text 1 and Supplementary Fig. 3 for details).

99 The STD version shows a greater increase of ocean heat uptake in response to the $\mathrm{CO}_{2}$

100 forcing, relative to the fixed-SSS-GL version (Fig. 2b). The greatest increase occurs in the tropical

101 and subtropical Atlantic Ocean and secondly in the subtropical South Pacific (Fig. 2b), broadly

102 mirroring regions where SSS shows the largest increase ${ }^{30}$ (Fig. 2c). The results support our

103 hypothesis on the role of sea surface salinification in enhancing heat penetration into the deeper

104 ocean by reduced density stratification resulting from upper-ocean warming. In response to the

$105 \mathrm{CO}_{2}$ forcing, the fixed-SSS-GL run shows a greater heat-equivalent buoyancy flux than the STD

106 run, which is partially attributed to freshwater flux (Supplementary Fig. 4), further demonstrating

107 the role of surface salinification in enhancing the buoyancy sink. The spatial distribution of SSS

108 change in response to the $\mathrm{CO}_{2}$ forcing (Fig. 2c) is broadly consistent with the change in P-E (Fig.

109 2d) strongly tied to the mean state (Supplementary Fig. 5), echoing the impact of the amplified

110 water cycle on surface salinity changes ${ }^{19-21,24}$.

111 However, we notice regions with mismatch between the OHC and SSS. First, the extension

112 of the positive $\mathrm{OHC}$ anomaly in the subtropical southeastern Pacific to the western Pacific

113 convective region (Fig. 2b) is not seen in the SSS pattern (Fig. 2c). This mismatch is primarily 
114 driven by the climatological oceanic transport toward the convective zone (Supplementary Fig.

115 6a-c); the change in ocean circulation is secondary (Supplementary Fig. 6d-f). Second, the

116 enhanced OHC anomaly in the subtropical North Atlantic over South Atlantic is not observed in

117 the SSS. The underlying reason will be addressed later in the discussion of the impact of ocean

118 circulation.
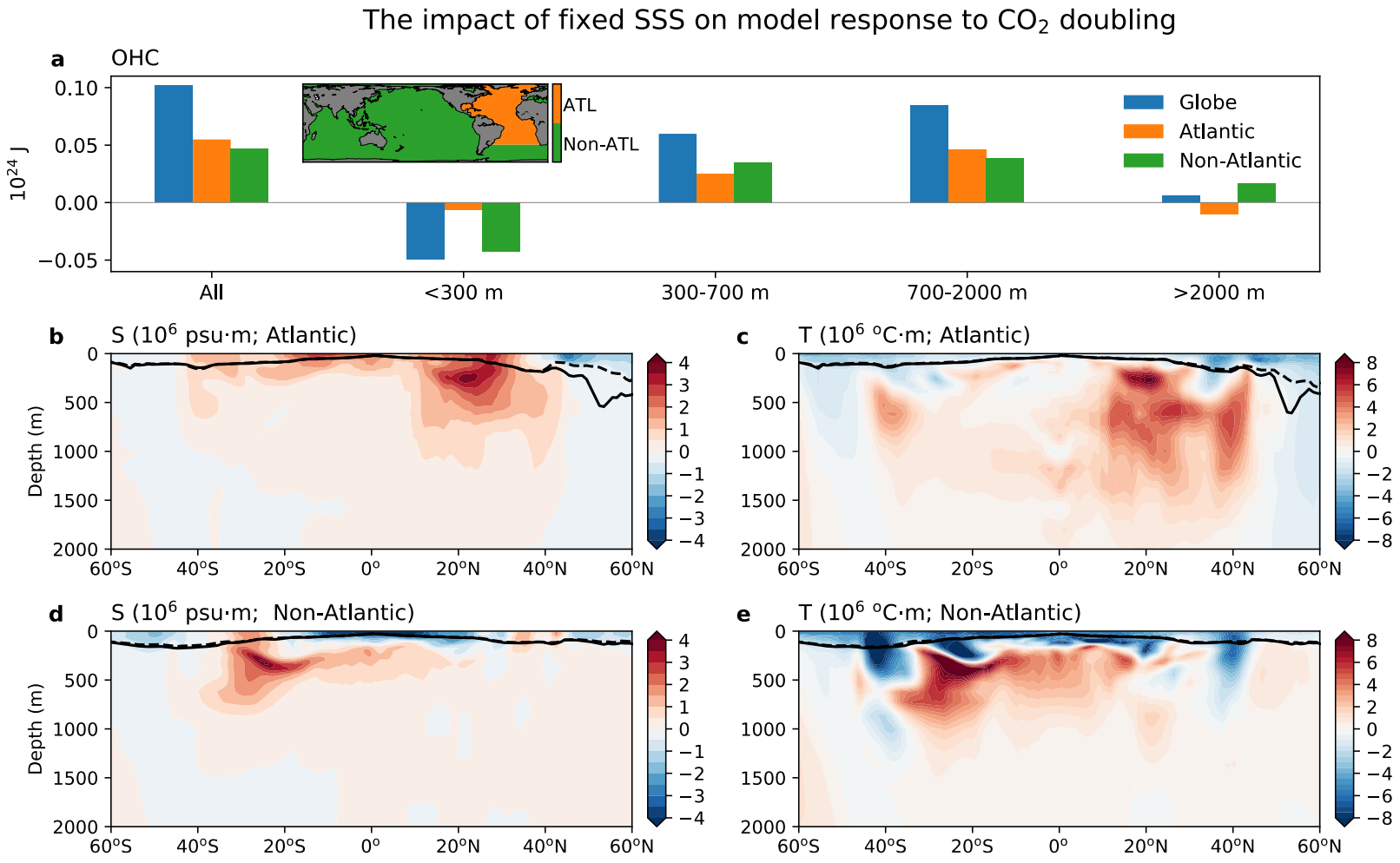

120 Fig. 3. Impact of fixed SSS on the model response to $\mathrm{CO}_{2}$ doubling. a, Difference in the

121 response of $\mathrm{OHC}\left(10^{24} \mathrm{~J}\right)$ to transient $\mathrm{CO}_{2}$ doubling between the STD and fixed-SSS-GL version

122 as a function of ocean depth. The response is computed using years 161-180 from the $\mathrm{CO}_{2}$ run

123 while years 101-200 from the control run. The inset figure indicates the area of Atlantic and non-

124 Atlantic Ocean for computing total OHC. b-c, Difference in the response of zonal-integral b ocean

125 salinity $\left(10^{6} \mathrm{psu} \cdot \mathrm{m}\right.$; color $)$ and $\mathbf{c}$ ocean temperature $\left(10^{6} \mathrm{C} \cdot \mathrm{m}\right.$; color $)$ between the STD and fixed-

126 SSS-GL version in the Atlantic using the same period as a. d-e, Same as in b-c, but for non- 
127 Atlantic Ocean. Black lines in b-d indicate winter mixed layer depth (mld; $\mathrm{m}$ ) from control runs

128 (solid) and $\mathrm{CO}_{2}$ runs (dashed), respectively. The mld is defined as the depth where the density

129 difference with respect to the surface level is greater than or equal to $0.03 \mathrm{~kg} \mathrm{~m}^{-3}$. The mld in $\mathbf{b}, \mathbf{d}$

130 are from the STD version while the mld in $\mathbf{c}, \mathbf{e}$ are from the fixed-SSS-GL version.

Relative to the fixed-SSS-GL version, the STD version exhibits deeper warming (Fig. 3a):

133 reduced increase of heating within the upper $300 \mathrm{~m}$, in agreement with the reduced increase of

134 surface temperature (Fig. 1). The downward shift of OHC arising from SSS changes is further

135 evident in the zonally-integrated subsurface temperature in response to $\mathrm{CO}_{2}$ doubling (Fig. 3c, e).

136 It is worth noting that, relative to the zonal mean, the zonal integral provides a more relevant

137 measure to compare tropics and subpolar regions by taking into account the difference in area per

138 unit latitude at different latitudes related to both the convergence of meridians and differences in

139 land mass. The Atlantic Ocean accounts for 54\% of all heat increase, and its greatest salinity-

140 induced increase of subsurface temperature occurs in the northern subtropics where the increase

141 of subsurface salinity also reaches its peak (Fig. 3b, c). For ocean basins other than the Atlantic,

142 there is also correspondence between the positive anomaly of subsurface temperature and salinity

143 as shown in the southern subtropics (Fig. 3d, e), primarily in the Pacific Ocean (Supplementary

144 Fig. 7b-c). Although the Indian Ocean shows a much smaller magnitude than the Pacific, the

145 positive salinity anomaly (e.g., around $20^{\circ}$ S) corresponds with upper-level cooling and deeper

146 ocean warming (Supplementary Fig. 7d-e). These results suggest the important role of increased

147 subsurface salinity in the subtropical ocean driven by surface salinification in modulating the

148 vertical distribution of heat through accelerated heat uptake. A consequence of heat sequestration

149 from the upper level to deeper ocean is the decrease in the upper-level thermal stratification (Fig. 
150 4e-f), which further increases the heat uptake through a positive feedback. The less thermal 151 stratification in the fixed-SSS-GL run relative to the STD run makes a considerable contribution 152 to the total difference in the upper ocean stratification (Fig. 4a-b), highlighting the important role 153 of this feedback in amplifying the salinification-driven reduction in stratification (Fig. 4c-d).
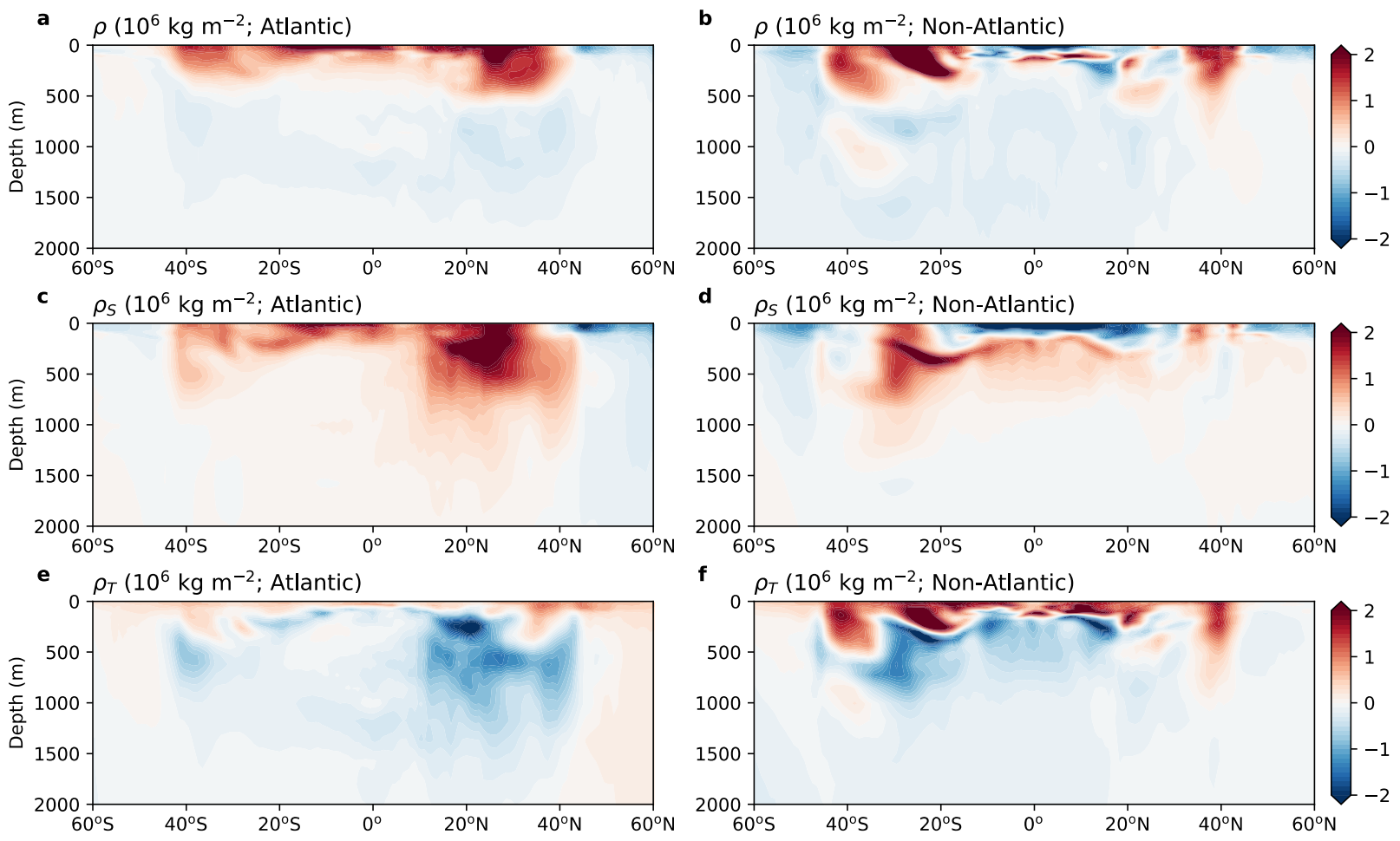

155 Figure. 4. Impact of fixed SSS on the response of ocean stratification to $\mathrm{CO}_{2}$ doubling. a-b,

Difference in the response of zonal-integral ocean density $\left(10^{6} \mathrm{~kg} \mathrm{~m}^{-2}\right)$ between the STD and fixed-

157 SSS-GL version for Atlantic and non-Atlantic Ocean, respectively. The response is computed

158 using years 161-180 from the $\mathrm{CO}_{2}$ run while years 101-200 from the control run. c-d, Same as a-

$159 \mathbf{b}$, but for the contribution of salinity to the difference in density change. e-f, Same as $\mathbf{a}-\mathbf{b}$, but for

160 the contribution of temperature to the difference in density change.

The wind-driven turbulent mixing in the upper layers seems to play a less important role

163 in the difference in OHC response between the two versions: 1) the mixed layer depth in winter 
164 shows insignificant difference between the two versions of FLOR in the subtropical ocean; 2) most

165 of the extra heat sink is sequestrated deeper than the mixed layer depth (Fig. 3c, e). The 166 intermediate layer (700-2000 m) sequesters more heat than other layers (Fig. 3a), in part driven by

167 increased heat penetration associated with the positive salinity anomaly (Fig. 3b, d). The 168 confinement of this salinity anomaly within the upper $1000 \mathrm{~m}$ (Fig. 3b, d) implies other 169 mechanisms, as will be discussed later, are needed to cause the extra heat increase in the lower 170 portion of the intermediate layer.

171 Given the importance of the ocean circulation in driving heat transports and related 172 temperature changes, we further investigated the role of the ocean circulation. Weakening of the 173 Atlantic Meridional Overturning Circulation (AMOC) in response to greenhouse gas forcing, as 174 seen in a number of previous studies ${ }^{32-34}$, is seen in the idealized $\mathrm{CO}_{2}$ doubling experiments with 175 FLOR (Supplementary Fig. 8). The fixed-SSS-GL version produces a less weakening of the 176 AMOC relative to the STD run, probably due to the suppression of the subpolar freshening by 177 climatological SSS nudging ${ }^{33}$. The greater AMOC weakening in the STD version results in a 178 reduced northward transport of warm water toward the subpolar North Atlantic and thus more heat 179 storage in the subtropics than the fixed-SS-GL version, which helps explain why the enhanced 180 OHC anomaly in the North Atlantic (Fig. 2c) is not seen in SSS (Fig. 2d).

181 The impact of the difference in the AMOC change is further explored by another set of 182 experiments that only nudge SSS in the subtropical Atlantic (labelled as fixed-SSS-subAtl; 183 Supplementary Fig. 9) to allow subpolar freshening. The fixed-SSS-subAtl version produces a 184 similar AMOC weakening relative to the STD run, allowing us to distinguish the relative role of 185 the $\mathrm{AMOC}$ and salinification on $\mathrm{OHC}$ changes. In response to the $\mathrm{CO}_{2}$ forcing, the STD version 186 shows a greater increase of OHC by $4.1 \times 10^{22} \mathrm{~J}$ relative to the fixed-SSS-subAtl version in the 
187 Atlantic Ocean (Supplementary Fig. 10a). This accounts for $74 \%$ of that relative to the fixed-SSS-

188 GL version, resulting from the competition between a greater OHC increase in subpolar Atlantic 189 and a smaller OHC increase at lower latitudes (Supplementary Fig. 11 versus Fig. 2b). This 190 meridional difference in OHC increase is partially attributed to the difference in AMOC weakening 191 between the fixed-SSS-subAtl and fixed-SSS-GL version. On the other hand, the greater 192 weakening of the AMOC in the fixed-SSS-subAtl than the fixed-SSS-GL version causes increased 193 salinity at lower latitudes due to reduced northward transport (Supplementary Fig. 12) and thus 194 enhances ocean heat uptake. The heat anomaly between the STD and fixed-SSS-subAtl version in 195 the subtropical North Atlantic overlaps with the positive salt anomaly (Supplementary Fig. 10b196 c), further implying the key role of salinification in accelerating heat uptake. In addition, the heat 197 anomaly is primarily sequestrated in the upper ocean $(<700 \mathrm{~m})$ (Supplementary Fig. 10c), in 198 contrast to the intermediate level (700-2000 m) for the heat anomaly between the STD and fixed199 SSS-GL version (Fig. 3). These results suggest the role of ocean circulation in heat sequestration 200 below the upper ocean for the following reasons. First, the enhanced northward transport of salty 201 water in the fixed-SSS-GL version relative to the fixed-SSS-subAtl experiment due to less AMOC 202 weakening could lead to decreased salt in the subtropics (Supplementary Fig. 12) and thus reduced 203 heat sink to deeper levels. Second, the enhanced southward import of North Atlantic Deep Water 204 in the fixed-SSS-GL version could transport more subpolar cold water to the intermediate level in 205 the subtropics, resulting in less warming than the other two experiments.

206 Besides fixed-SSS-subAtl, we conducted another set of experiments that partially nudged 207 SSS in non-Atlantic ocean basins (labelled as fixed-SSS-nonAtl; Supplementary Fig. 13). The 208 fixed-SSS-nonAtl version shows a lesser weakening of the AMOC than the fixed-SSS-subAtl 209 version, probably due to the subtropical Atlantic salinification driven by enhanced hydrological 
210 drying (Fig. 2d). The sea water with enhanced salinity moves northward, leading to a lower ocean

211 stratification in the subpolar region and a stronger AMOC. However, the weakening of the AMOC

212 in the fixed-SSS-nonAtl version is closer to the STD version than the fixed-SSS-GL version,

213 resulting in reduced impact from the AMOC on OHC changes (Supplementary Fig. 8). Outside of

214 the Atlantic, the fixed-SSS-nonAtl version exhibits similar changes of $\mathrm{OHC}$ and subsurface

215 temperature (Supplementary Fig. 14a, e) to the fixed-SSS-GL version (Fig. 3a, e), which is

216 dominated by the Pacific Ocean (Supplementary Fig. 15a, e). The correspondence between salinity

217 and temperature in the subtropics further demonstrates the important role of salinification in

218 enhancing ocean heat uptake.

219 We compare the simulated model response with observations to explore the impact of 220 increased $\mathrm{CO}_{2}$ on the current climate change. The linear trend of SSS from an observational data 221 set spanning the period of 1968-2017 from National Centers for Environmental Information 222 (NCEI) ${ }^{16}$ resembles the spatial pattern of SSS change seen in the idealized FLOR experiments 223 (Supplementary Fig. 16a), a resemblance that is robust across different observationally-based 224 ocean salinity data sets (Supplementary Fig. 16b-d), suggesting the emergent signal of human225 induced forcing in shaping the observed changes of ocean salinity, as identified by a number of 226 recent studies ${ }^{22,30,31}$. The similarity is not seen in the subpolar North Atlantic where SSS shows an 227 increase in FLOR while decrease in observations. The underlying reason will be discussed later.

228 Similar to SSS, the simulated response of ocean subsurface temperature and salinity to the 229 idealized $\mathrm{CO}_{2}$ forcing from the STD version also resembles many key features in the linear trend 230 of observations spanning the period of 1968-2017 (Fig. 5), implying the likely emergent signal of 231 human-induced forcing in driving the temperature and salinity changes $22,30,31,35$. This similarity is 232 broadly robust across data sets (Supplementary Figs. 17-19). 
Model response to $\mathrm{CO}_{2}$ doubling

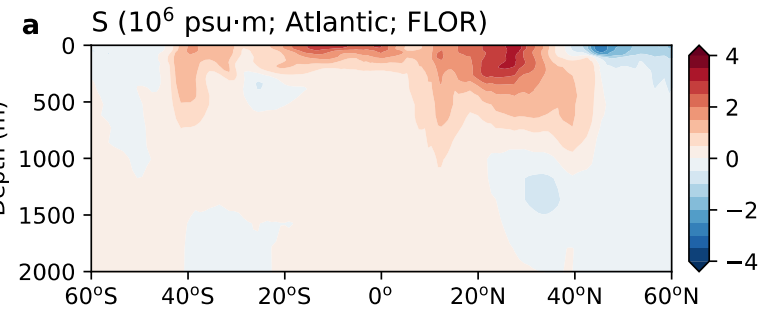

b $\mathrm{T}\left(10^{6}{ }^{\circ} \mathrm{C} \cdot \mathrm{m} ;\right.$ Atlantic; FLOR $)$

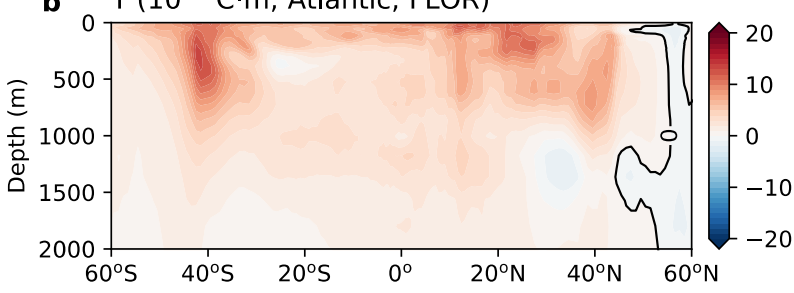

c $\mathrm{S}\left(10^{6} \mathrm{psu} \cdot \mathrm{m} ;\right.$ Non-Atlantic; FLOR)

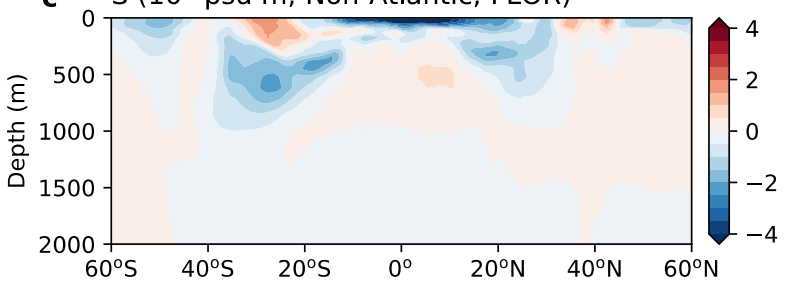

d $\mathrm{T}\left(10^{6}{ }^{\circ} \mathrm{C} \cdot \mathrm{m}\right.$; Non-Atlantic; FLOR $)$

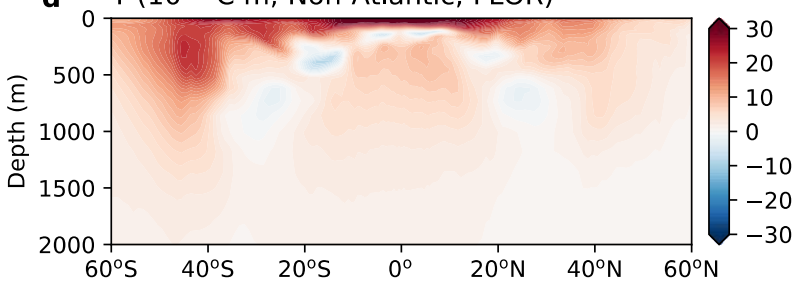

Observation

e $\mathrm{S}\left(10^{6} \mathrm{psu} \cdot \mathrm{m} / 50 \mathrm{yr} ;\right.$ Atlantic; NCEI)

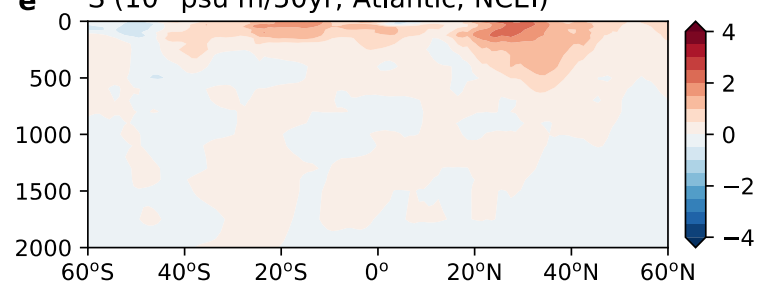

f $\mathrm{T}\left(10^{6}{ }^{\circ} \mathrm{C} \cdot \mathrm{m} / 50 \mathrm{yr} ;\right.$ Atlantic; NCEI)

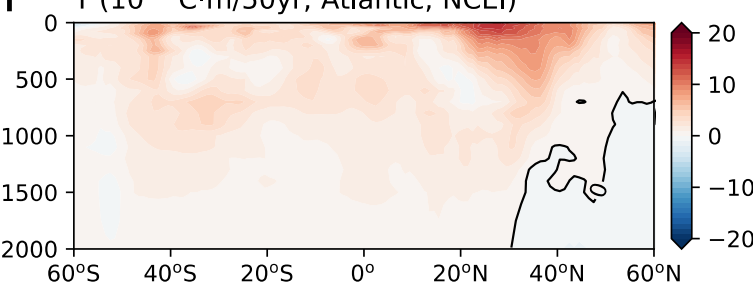

g $\mathrm{S}\left(10^{6} \mathrm{psu} \cdot \mathrm{m} / 50 \mathrm{yr} ;\right.$ Non-Atlantic; NCEI)

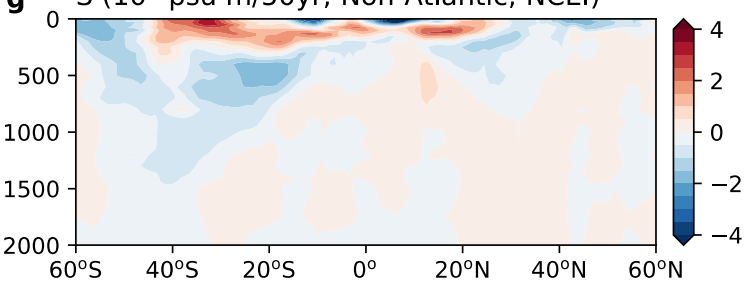

h $\quad \mathrm{T}\left(10^{6}{ }^{\circ} \mathrm{C} \cdot \mathrm{m} / 50 \mathrm{yr} ;\right.$ Non-Atlantic; NCEI $)$

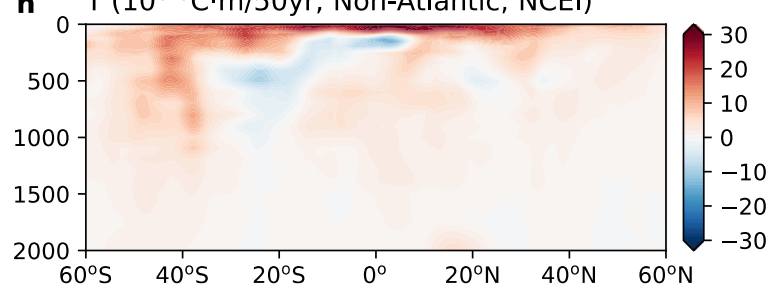

234 Fig. 5. Comparison between FLOR model experiments and observations. a-b, Change in

235 zonal-integral a ocean subsurface salinity $\left(10^{6} \mathrm{psu} \cdot \mathrm{m}\right.$; color $)$ and b ocean temperature $\left(10^{6}{ }^{\circ} \mathrm{C} \cdot \mathrm{m}\right.$;

236 color) in response to transient $\mathrm{CO}_{2}$ doubling in the Atlantic Ocean for the STD runs. c-d, Same as

237 in $\mathbf{a - b}$, but for non-Atlantic Ocean. The response is computed using years 161-180 from the $\mathrm{CO}_{2}$

238 run while years 101-200 from the control run. e-h, Same as in a-d, but the linear trend of ocean

239 salinity $\left(10^{6} \mathrm{psu} \cdot \mathrm{m} / 50 \mathrm{yr}\right)$ and temperature $\left(10^{6} \mathrm{C} \cdot \mathrm{m} / 50 \mathrm{yr}\right)$ from the NCEI data over the period of

240 1968-2017. The trend is tuned by the ratio of $\mathrm{CO}_{2}$ concentration at $\mathrm{CO}_{2}$ doubling in FLOR to that

241 in 2017 from observations. 
In the Atlantic Ocean, both the STD simulations and in situ data show a positive salt

244 anomaly (Fig. 5a, e) overlapped with the heat anomaly (Fig. 5b, f) in the subtropics which, as

245 demonstrated in the FLOR experiments, is primarily driven by subtropical surface salinification

246 associated with intensified hydrological cycle. Similar to SSS (Fig. 2c versus Supplementary Fig.

247 16), a major difference lies in the subpolar North Atlantic where the decrease of subsurface salinity

248 and temperature in FLOR, especially in the upper ocean, is less clear in observations, primarily

249 driven by their difference in AMOC changes. AMOC weakening in response to $\mathrm{CO}_{2}$ forcing in the

250 standard FLOR experiment (Supplementary Fig. 8) is not seen in the past few decades due to

251 strong decadal variability ${ }^{36,37}$, although recent studies employing proxy data claimed the century-

252 scale weakening of the $\mathrm{AMOC}^{38,39}$.

253 For ocean basins other than the Atlantic, both the STD simulations and observations show

254 decreased salinity in the upper ocean extending to $1000 \mathrm{~m}$ in subtropics (Fig. 5c, g), broadly

255 overlapping with the regions with cooling (Fig. 5d, h). Although the surface salinification in the

256 south subtropics from the STD version does not exceed the rate of freshening beneath (Fig. 5c), it

257 leads to more salt and heat penetration into deeper layers than the fixed-SSS-GL version in which

258 the surface salinification is suppressed (Fig. 3d-e). The $40^{\circ}-50^{\circ} \mathrm{S}$ zone of the Southern Ocean

259 shows substantial warming (Fig. 5b, d), which is claimed in a recent work ${ }^{40}$ to result from the

260 northward heat transport associated with the Antarctic Circumpolar Current.

261 In this study, we highlight the previously overlooked role of subtropical salinification-

262 driven by the enhanced water cycle ${ }^{19-24}$ in response to greenhouse warming -in accelerating the

263 rate of ocean heat uptake and thus moderating transient climate warming. By a set of climate model

264 experiments we find that the largest enhancement in ocean heat uptake occurs in the subtropical

265 South Pacific and the tropical and subtropical Atlantic Ocean, where SSS shows the greatest 
266 increase. The results also highlight the role of salinification in modulating the vertical distribution

267 of subsurface temperature by sequestrating upper-level heat to deeper ocean, which could lead to

268 reduced thermal stratification and further enhance ocean heat uptake through a positive feedback.

269 Without the surface salinification, the FLOR experiments suggest that the TCR could increase by

$2700.4 \mathrm{~K}$, close to the standard deviation of TCR from the CMIP6 models ${ }^{41}$. This suggests that the

271 multi-model spread in transient climate sensitivity may be partially traced to their spread in

272 simulating ocean salinity. The increasing emergence of the anthropogenic signal in the ocean water

273 masses $^{35}$ raises the need for future research of the competing mechanism between upper ocean

274 warming and subtropical salinification in ocean stratification, which is critical for improved

275 understanding of past and future ocean heat uptake and transient climate change.

276 


\section{Reference}

278 1. Mitchell, J. F. B., Manabe, S., Meleshko, V. \& Tokioka, T. Equilibrium climate change 279 and its implications for the future. Clim. Chang. IPCC Sci. Assess. 131, 172 (1990).

280 2. Cheng, L., Abraham, J., Hausfather, Z. \& Trenberth, K. E. How fast are the oceans $281 \quad$ warming? Science (80-. ). 363, 128 LP - 129 (2019).

282 3. Trenberth, K. E., Fasullo, J. T. \& Balmaseda, M. A. Earth's energy imbalance. J. Clim. $283 \quad 27,3129-3144$ (2014).

284 4. Li, G. et al. Increasing ocean stratification over the past half-century. Nat. Clim. Chang. 285 (2020). doi:10.1038/s41558-020-00918-2

286 5. Stevens, S. W., Johnson, R. J., Maze, G. \& Bates, N. R. A recent decline in North Atlantic 287 subtropical mode water formation. Nat. Clim. Chang. 10, (2020).

288 6. Ishii, M. et al. Accuracy of Global Upper Ocean Heat Content Estimation Expected from 289 Present Observational Data Sets. Sola 13, 163-167 (2017).

290 7. Cheng, L. et al. Improved estimates of ocean heat content from 1960 to 2015. Sci. Adv. 3, $291 \quad 1-10(2017)$.

292 8. Domingues, C. M. et al. Improved estimates of upper-ocean warming and multi-decadal 293 sea-level rise. Nature 453, 1090-1093 (2008).

294 9. Abraham, J. P. et al. A review of global ocean temperature observations: Implications for 295 ocean heat content estimates and climate change. Rev. Geophys. 51, 450-483 (2013).

296 10. von Schuckmann, K. et al. Heat stored in the Earth system: where does the energy go? 297 Earth Syst. Sci. Data 12, 2013-2041 (2020).

298 11. Meyssignac, B. et al. Measuring Global Ocean Heat Content to Estimate the Earth Energy 299 Imbalance . Frontiers in Marine Science 6, 432 (2019). 
12. Taylor, K. E., Stouffer, R. J. \& Meehl, G. A. An Overview of CMIP5 and the Experiment 301 Design. Bull. Am. Meteorol. Soc. 93, 485-498 (2012).

302 13. Larson, E. J. L., Portmann, R. W., Solomon, S. \& Murphy, D. M. Decadal Attribution of 303 Historic Temperature and Ocean Heat Content Change to Anthropogenic Emissions. Geophys. Res. Lett. 47, e2019GL085905 (2020).

305 14. Bronselaer, B. \& Zanna, L. Heat and carbon coupling reveals ocean warming due to 306

16. Levitus, S. et al. World ocean heat content and thermosteric sea level change (0-2000 m), 1955-2010. Geophys. Res. Lett. 39, (2012).

312 17. Vecchi, G. A. et al. Tropical cyclone sensitivities to CO2 doubling: roles of atmospheric 313 resolution, synoptic variability and background climate changes. Clim. Dyn. (2019). doi:10.1007/s00382-019-04913-y

315 18. Capotondi, A., Alexander, M. A., Bond, N. A., Curchitser, E. N. \& Scott, J. D. Enhanced upper ocean stratification with climate change in the CMIP3 models. J. Geophys. Res.

318 19. Durack, P. J. \& Wijffels, S. E. Fifty-Year trends in global ocean salinities and their 319 relationship to broad-scale warming. J. Clim. 23, 4342-4362 (2010).

320 20. Durack, P. J., Wijffels, S. E. \& Matear, R. J. Ocean Salinities Reveal Strong Global Water 321 Cycle Intensification During 1950 to 2000. Science (80-. ). 336, 455 LP - 458 (2012).

322 21. Skliris, N. et al. Salinity changes in the World Ocean since 1950 in relation to changing 
surface freshwater fluxes. Clim. Dyn. 43, 709-736 (2014).

324 22. Terray, L. et al. Near-surface salinity as nature's rain gauge to detect human influence on

325 the Tropical water cycle. J. Clim. (2012). doi:10.1175/JCLI-D-10-05025.1

326 23. Lago, V. et al. Simulating the role of surface forcing on observed multidecadal upperocean salinity changes. J. Clim. (2016). doi:10.1175/JCLI-D-15-0519.1

328 24. Held, I. M. \& Soden, B. J. Robust responses of the hydrological cycle to global warming. 329 J. Clim. (2006). doi:10.1175/JCLI3990.1

330 25. Stocker, T. F. et al. Climate change 2013 the physical science basis: Working Group I contribution to the fifth assessment report of the intergovernmental panel on climate change. Climate Change 2013 the Physical Science Basis: Working Group I Contribution to the Fifth Assessment Report of the Intergovernmental Panel on Climate Change (2013).

26. Bindoff, N. L. et al. Changing ocean, marine ecosystems, and dependent communities. IPCC Spec. Rep. Ocean Cryosph. a Chang. Clim. 477-587 (2019).

337 27. Vecchi, G. A. et al. On the Seasonal Forecasting of Regional Tropical Cyclone Activity. J. Clim. 27, 7994-8016 (2014).

339 28. Gregory, J. M. \& Mitchell, J. F. B. The climate response to CO2 of the Hadley Centre 340 coupled AOGCM with and without flux adjustment. Geophys. Res. Lett. (1997). doi:10.1029/97GL01930

342 29. Raper, S. C. B., Gregory, J. M. \& Stouffer, R. J. The role of climate sensitivity and ocean 343 heat uptake on AOGCM transient temperature response. J. Clim. (2002). doi:10.1175/1520-0442(2002)015<0124:trocsa>2.0.co;2

345 30. Stott, P. A., Sutton, R. T. \& Smith, D. M. Detection and attribution of Atlantic salinity 
changes. Geophys. Res. Lett. (2008). doi:10.1029/2008GL035874

347 31. Pierce, D. W., Gleckler, P. J., Barnett, T. P., Santer, B. D. \& Durack, P. J. The fingerprint of human-induced changes in the ocean's salinity and temperature fields. Geophys. Res. Lett. 39, 2-7 (2012).

350 32. Stouffer, R. J. et al. Investigating the cause of the response of the thermohaline circulation to past and future climage changes. J. Clim. 19, 1365-1387 (2006).

352 33. Liu, W., Fedorov, A. V, Xie, S.-P. \& Hu, S. Climate impacts of a weakened Atlantic Meridional Overturning Circulation in a warming climate. Sci. Adv. 6, eaaz4876 (2020).

354 34. Levang, S. J. \& Schmitt, R. W. What Causes the AMOC to Weaken in CMIP5? J. Clim. $355 \quad 33,1535-1545(2019)$.

356 35. Silvy, Y., Guilyardi, E., Sallée, J.-B. \& Durack, P. J. Human-induced changes to the global ocean water masses and their time of emergence. Nat. Clim. Chang. (2020). doi:10.1038/s41558-020-0878-X

359 36. Robson, J., Ortega, P. \& Sutton, R. A reversal of climatic trends in the North Atlantic since 2005. Nat. Geosci. 9, 513-517 (2016).

361 37. Jackson, L. C., Peterson, K. A., Roberts, C. D. \& Wood, R. A. Recent slowing of Atlantic 362 363 overturning circulation as a recovery from earlier strengthening. Nat. Geosci. 9, 518-522 (2016).

364 38. Thornalley, D. J. R. et al. Anomalously weak Labrador Sea convection and Atlantic overturning during the past 150 years. Nature 556, 227-230 (2018).

366 39. Caesar, L., Rahmstorf, S. \& Feulner, G. On the relationship between Atlantic meridional 367 overturning circulation slowdown and global surface warming. Environ. Res. Lett. 15, 368 24003 (2020). 
369 40. Armour, K. C., Marshall, J., Scott, J. R., Donohoe, A. \& Newsom, E. R. Southern Ocean

370 warming delayed by circumpolar upwelling and equatorward transport. Nat. Geosci.

$371 \quad$ (2016). doi:10.1038/ngeo2731

372 41. Meehl, G. A. et al. Context for interpreting equilibrium climate sensitivity and transient

373 climate response from the CMIP6 Earth system models. Science Advances (2020).

374 doi:10.1126/sciadv.aba1981

375 


\section{Method}

377 Model experiments.

We use the Forecast-oriented Low Ocean Resolution model (FLOR) ${ }^{27,42}$ developed at

379 Geophysical Fluid Dynamics Laboratory (GFDL). FLOR has a horizontal resolution of 380 approximately $50 \mathrm{~km}$ for the atmosphere and land components developed from GFDL Coupled 381 Model $(\mathrm{CM})$ version 2.5 and a coarser $\left(\sim 1^{\circ}\right)$ resolution for the oceanic and sea ice components 382 from GFDL CM version 2.1. We use the FLOR model to conduct a set of fully-coupled 383 experiments. The first experiment is labeled as a standard control simulation in which the radiative 384 forcing and land use/land cover is maintained as the level of year 1990 for 200 years. The first 100 385 years were treated as model spin-up and discarded from further analyses. Beside the standard 386 control simulation, we also carried out three control experiment in which the sea surface salinity 387 (SSS) of the fully-coupled model is "nudged" to the climatological SSS over the global ocean 388 (labeled as fixed-SSS-GL), the subtropical Atlantic Ocean (Supplementary Fig. 9; labeled as fixed389 SSS-subAtl) and non-Atlantic ocean basins (Supplementary Fig. 13; labeled as fixed-SSS-nonAtl), 390 respectively, using model year 101 in the standard control simulation for the initial condition. 391 Corresponding to each standard control simulation, we conducted a perturbation experiment in 392 which the atmospheric $\mathrm{CO}_{2}$ concentration was increased at a rate of $1 \%$ per year until doubling 393 from year 101 (i.e., 100 years after model initialization), and was then held fixed. For each 394 experiment, the climate response to $\mathrm{CO}_{2}$ doubling is computed as difference between model year 395 161-180 from the perturbation run and model year 101-200 from the control run.

396 Radiative feedback computations.

397 We use the radiative kernel method ${ }^{43}$ to calculate the transient radiative feedbacks for the $398 \mathrm{CO}_{2}$ stabilization period (i.e., year 161-180). The radiative kernel for a feedback variable $x$ is 
399 defined as $K^{x}=\partial R / \partial x$, in which $R$ is the net top-of-atmosphere (TOA) flux, and $\mathrm{x}$ is an individual

400 radiative state variable (e.g., temperature, water vapor, clouds, or surface albedo). The radiative

401 kernel is derived from CloudSat/CALIPSO measurements ${ }^{44,45}$.

402 Ocean heat content analysis.

403 The ocean heat content is computed as follows:

404

$$
O H C=\int_{x_{1}}^{x_{2}} \int_{y_{1}}^{y_{2}} \int_{z_{1}}^{z_{2}} \rho C_{P} T d x d y d z
$$

405 in which $\rho$ is the density of sea water, $C_{P}$ is the specific heat capacity, $T$ is the temperature, $x_{1}$ and $406 x_{2}$ denote the western and eastern boundaries of the ocean, $y_{1}$ and $y_{2}$ denote the southern and 407 northern boundaries, and $z_{1}$ and $z_{2}$ denote the range of the ocean depth.

408 Surface buoyancy flux analysis.

409 The surface buoyancy flux $(B)$ is composed of contributions from both heat $\left(B_{H}\right)$ and freshwater $410 \quad$ flux $\left(B_{F W}\right)^{46}$ :

$$
B=B_{H}+B_{F W}=\frac{g}{\rho_{0}}\left[\left(\alpha Q_{H} / c_{p}\right)+\rho_{0} \beta S(P-E+R)\right]
$$

412 in which $g$ is the gravitational acceleration, $\rho_{0}$ is a reference density, $\alpha$ and $\beta$ are the thermal 413 expansion and saline contraction coefficients, respectively, $c_{p}$ is the specific heat capacity of 414 seawater, $S$ is the sea surface salinity, $Q_{H}$ is the air-sea heat flux $\left(\mathrm{W} \mathrm{m}^{-2}\right), P$ is precipitation, $E$ is 415 evaporation, and $R$ is runoff into the ocean. For a more convenient comparison, both the buoyancy 416 and freshwater flux are expressed as heat-equivalent flux, denoted as $Q_{B}$ and $Q_{F W}$, respectively ${ }^{46}$. 417 The heat-equivalent buoyancy flux is:

$$
Q_{B}=Q_{H}+Q_{F W}=\frac{\rho_{0} c_{p}}{g \alpha} B
$$

419 and the heat-equivalent freshwater flux is:

$$
Q_{F W}=\frac{\rho_{0} c_{p}}{g \alpha} B_{F W}
$$


421 Ocean density analysis.

422 We decompose the response of ocean density to $\mathrm{CO}_{2}$ forcing $(\Delta \rho)$ by computing the relative 423 contributions from both salinity $\left(\Delta \rho_{S}\right)$ and temperature $\left(\Delta \rho_{T}\right)$ :

$$
\Delta \rho=\rho_{\mathrm{CO}_{2}}-\rho
$$

$$
\Delta \rho_{S}=\beta \Delta S \rho-\rho
$$

$$
\Delta \rho_{T}=-\alpha \Delta T \rho-\rho
$$

427 in which $\rho_{\mathrm{CO}_{2}}$ is the ocean density from years 161-180 in the $\mathrm{CO}_{2}$ run, $\rho$ is the ocean density from 428 years 101-200 in the control run, $\Delta S$ and $\Delta T$ are the response of salinity and temperature to $\mathrm{CO}_{2}$ 429 doubling, respectively, $\beta$ is the haline contraction coefficient, and $\alpha$ is the thermal expansion 430 coefficient.

431 Ocean salinity and temperature data.

432 We use four gridded data sets of ocean salinity and temperature for the period of 1968433 2017. The first three data sets constructed based on in situ measurements are National Centers for 434 Environmental Information (NCEI), United States ${ }^{16}$, Japan Meteorological Agency (JMA), Japan ${ }^{6}$ 435 and Institute of Atmospheric Physics (IAP), China ${ }^{7,47}$. We also use an ocean reanalysis product 436 from Ocean Reanalysis System 4 (ORAS4) ${ }^{48}$ that constrains the model simulations with in situ 437 measurements. The linear trend of ocean salinity and temperature spanning from 1968 to 2017 is 438 computed using an ordinary least-square linear fit and then multiplied by 50 to represent changes. 439 Before comparing the trend to FLOR-simulated change, we tuned it roughly by the ratio of $\mathrm{CO}_{2}$ 440 concentration at $\mathrm{CO}_{2}$ doubling in FLOR (708 ppm) to that in 2017 (407 ppm) from observations. 441 By extrapolating the trend, we focus on the linear component of the response of subsurface salinity 442 and temperature to the $\mathrm{CO}_{2}$ forcing. It is worth noting that linearity is an important component of 443 the changing trend of observed $\mathrm{CO}_{2}$ concentrations (Supplementary Fig. 20). 
445 42. Jia, L. et al. Improved Seasonal Prediction of Temperature and Precipitation over Land in 446 a High-Resolution GFDL Climate Model. J. Clim. 28, 2044-2062 (2015).

447 43. Soden, B. J. et al. Quantifying Climate Feedbacks Using Radiative Kernels. J. Clim. 21, $448 \quad 3504-3520(2008)$.

449 44. Zhang, B., Kramer, R. J. \& Soden, B. J. Radiative Feedbacks Associated with the 450 Madden-Julian Oscillation. J. Clim. 32, 7055-7065 (2019).

451 45. Kramer, R. J., Matus, A. V, Soden, B. J. \& L'Ecuyer, T. S. Observation-Based Radiative 452 Kernels From CloudSat/CALIPSO. J. Geophys. Res. Atmos. 124, 5431-5444 (2019).

453 46. Cerovečki, I., Talley, L. D. \& Mazloff, M. R. A Comparison of Southern Ocean Air-Sea 454 Buoyancy Flux from an Ocean State Estimate with Five Other Products. J. Clim. 24, $455 \quad 6283-6306$.

456 47. Cheng, L. et al. Improved estimates of changes in upper ocean salinity and the 457 hydrological cycle. J. Clim. 1-74 (2020). doi:10.1175/JCLI-D-20-0366.1

458 48. Balmaseda, M. A., Mogensen, K. \& Weaver, A. T. Evaluation of the ECMWF ocean 459 reanalysis system ORAS4. Q. J. R. Meteorol. Soc. (2013). doi:10.1002/qj.2063 
463 The NCEI ocean salinity and temperature data is available at 464 https://www.nodc.noaa.gov/OC5/3M_HEAT_CONTENT/. The JMA data is available at 465 https://climate.mri-jma.go.jp/pub/ocean/ts/v7.3/. The IAP data is available at 466 http://159.226.119.60/cheng/. The ORAS4 data is available at ftp://ftp-icdc.cen.uni467 hamburg.de/EASYInit/ORA-S4/. The processed data for graphics from the four data sets and 468 FLOR model outputs are available at tigress-web at Princeton University (http://tigress469 web.princeton.edu/ maofeng/SSS_OHU_TCR/data/).

\section{Code availability}

472 The climate model used in this study is GFDL FLOR with code available at the NOAA/GFDL 473 website (https://www.gfdl.noaa.gov/cm2-5-and-flor/). All graphics are produced using Python 474 version 3.6 (https://www.python.org/downloads/release/python-360/). The Python scripts are 


\section{Acknowledgements}

480 This work was supported by Award 80NSSC20K0879 from the National Aeronautics and Space

481 Administration and Award DE-SC0021333 from the U.S. Department of Energy. The simulations

482 presented in this paper were performed on computational resources managed and supported by

483 Princeton Research Computing at Princeton University.

484

485

486

487

488

\section{Corresponding Author}

Correspondence and requests for materials should be addressed to M.L.

\section{Author contributions}

B.S., G.V. and M.L. designed the research; G.V., M.L. and W.Y. performed the simulations; interpretation of the results and the writing of the paper.

494 The authors declare no competing financial interests. 